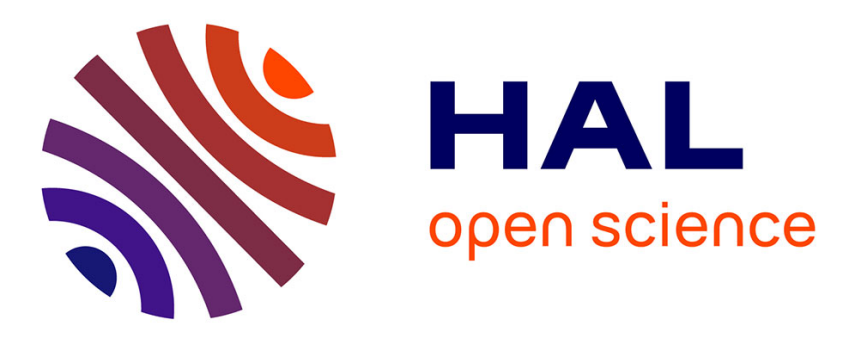

\title{
Small angle neutron scattering (SANS) investigation of irradiated manet steel
}

\author{
G. Albertini, F. Carsughi, M. Ceretti, R. Coppola, F. Fiori, A. Möslang, F. \\ Rustichelli
}

\section{- To cite this version:}

G. Albertini, F. Carsughi, M. Ceretti, R. Coppola, F. Fiori, et al.. Small angle neutron scattering (SANS) investigation of irradiated manet steel. Journal de Physique IV Proceedings, 1993, 03 (C8), pp.C8-283-C8-286. 10.1051/jp4:1993855 . jpa-00252286

\section{HAL Id: jpa-00252286 https://hal.science/jpa-00252286}

Submitted on 1 Jan 1993

HAL is a multi-disciplinary open access archive for the deposit and dissemination of scientific research documents, whether they are published or not. The documents may come from teaching and research institutions in France or abroad, or from public or private research centers.
L'archive ouverte pluridisciplinaire HAL, est destinée au dépôt et à la diffusion de documents scientifiques de niveau recherche, publiés ou non, émanant des établissements d'enseignement et de recherche français ou étrangers, des laboratoires publics ou privés. 


\section{Small angle neutron scattering (SANS) investigation of irradiated manet steel}

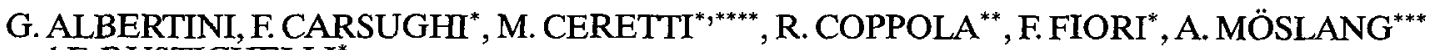
and F. RUSTICHELLI ${ }^{*}$

Dipartimento di Scienze dei Materiali e della Terra, Università, Via Brecce Bianche, 60131 Ancona, Italy * Istituto di Scienze Fisiche, Università, Via Ranieri 65, 60131 Ancona, Italy

** ENEA Casaccia, C.P. 2400, 00100 Roma, Italy

*** KfK, Institut f. Materialforschung I, Postfach 3640, 7500 Karlsruhe, Germany

**** LLB-Saclay, Laboratoire Commun CEA-CNRS, 91191 Gif-sur-Yvette, France

Abstract. SANS was used to investigate the growth of He-bubbles in a martensitic steel developed for fusion reactors ("MANET"). The investigated sample were simultaneously irradiated at high temperature with high-energy protons and alpha particles and then submitted to fatigue. Differences in the SANS curves were observed between the irradiated and non irradiated samples; they were attributed to radiation induced inhomogeneities and in particular to helium bubbles

\section{INTRODUCTION}

The so called "first-wall" of the future tokamak-based reactors, such as NET/ITER (Next European Torus / International Thermonuclear Experimental Reactor), will directly face the burning plasma and undergo extreme service conditions, including high-energy neutron irradiation and intense thermomechanical stresses. Therefore first-wall materials must be submitted to irradiation tests which reproduce as much as possible the real working environment and their microstructural evolution must carefully be investigated, especially regarding the growth of He-bubbles.

This contribution presents the results of a SANS investigation on modified martensitic steel DIN 1.4914, or "MANET", developed as a possible structural material for some test sectors in NET [1] or in more advanced reactors. The investigated samples were irradiated at the Dual-Beam facility in KfK [2], that is submitted to simultaneous high-energy protons and alpha particles implantation and subsequently to fatigue. This kind of treatment is quite representative of the anticipated working conditions of the first-wall and the mechanical data it yields have great technological relevance to evaluating the behaviour of the first-wall materials. 
Since it is also very important to understand the complex corresponding microstructural effects, SANS was used to investigate the presence of $\mathrm{He}$ bubbles as this technique has already been succesfully employed in this same steel [3-5].

Details on the sample preparation are given in the next section. The SANS results are presented and discussed in the following one.

\section{INVESTIGATED SAMPLES}

The chemical composition of the investigated material is reported in Tab. 1.

Table 1:

Chemical composition of the martesitic steel DIN 1.4914 MANET (in wt\%)

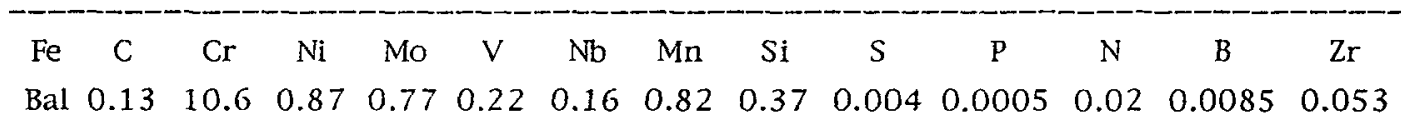

The specimens were irradiated at $450^{\circ} \mathrm{C}$ at the High-Energy Dual-Beam Facility of KfK - Karlsruhe (Germany) (a-energy $\leq 104 \mathrm{MeV}: \alpha$-dose: $\approx 200$ appm): a $30 \mathrm{MeV}$ proton beam adjusted the damage to 1.2 dpa [6]. After implantation they were subjected to mechanical cycling at $450^{\circ} \mathrm{C}$, which included a two minute hold at the maximum tensile strain.

A non irradiated specimen submitted to the same thermo-mechanic history was. used as a reference.
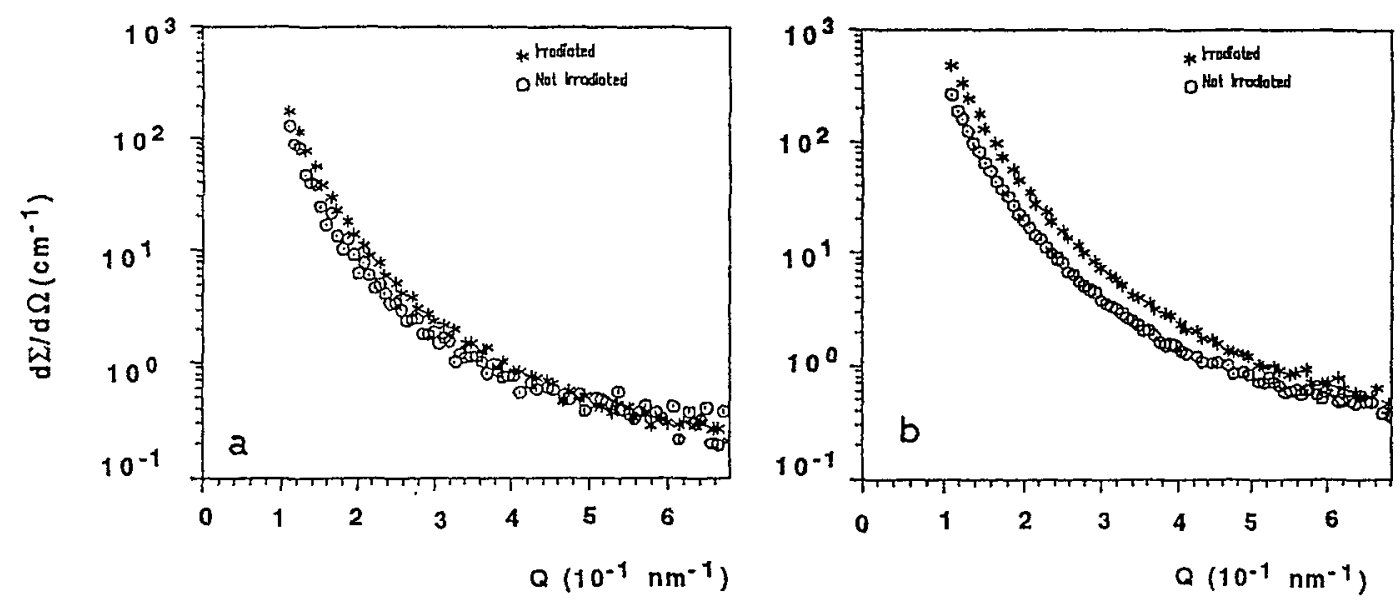

Fig. 1 SANS curve from the irradiated $(*)$ and non irradiated (o) samples.

(a) parallel to the magnetic field (nuclear scattering);

(b) perpendicular to the magnetic field (nuclear and magnetic scattering). 
The results of fatigue-tests and of transmission electron microscopy (TEM) observations on these samples are reported in [6].

The SANS specimens, obtained from the original ones, were empty cylinders (cylinder axis parallel to the stress direction) $5 \mathrm{~mm}$ high, with internal radius of $8 \mathrm{~mm}$ and external radius of $8.8 \mathrm{~mm}$.

\section{RESULTS AND DISCUSSION}

The SANS measurements were performed by using the PAXY instrument of the Laboratoire Leon Brillouin (Laboratoire Comm. CEA - CNRC, CE-Saclay). A wavelength of $1 \mathrm{~nm}$ and a $3 \mathrm{~m}$ sample-to-detector distance were used, corresponding to a Q-range from $8 \cdot 10^{-2}$ to $7.5 \cdot 10^{-1} \mathrm{~nm}^{-1}$; this means that particle sizes from few nanometers to few tenths of nanometers could be detected by the present experiment.
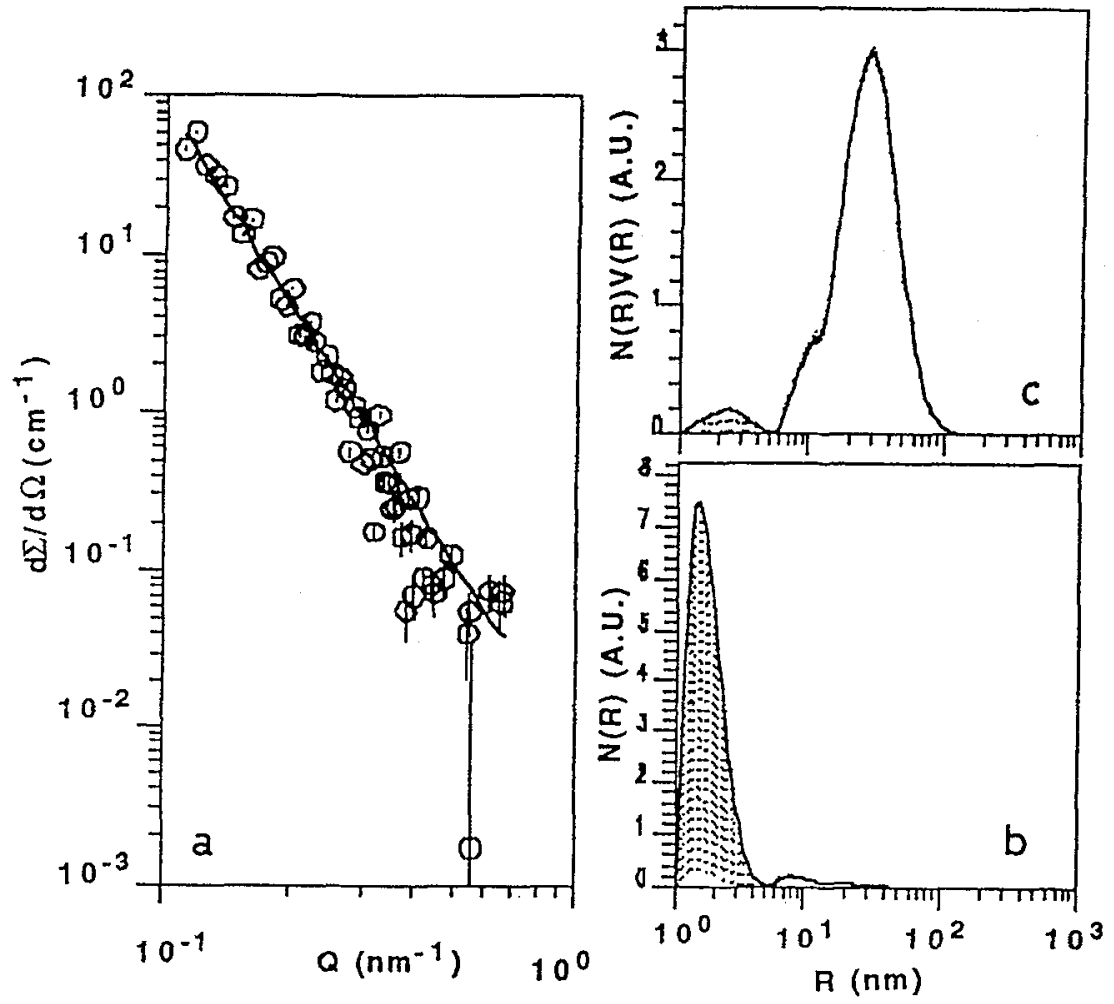

Fig. 2 (a) SANS curve from nuclear inhomogeneities induced by dual-beam irradiation. Experimental data ( $O$ ) and best-fit curve (line).

(b) Size distribution of nuclear inhomogeneities.

(c) Volume distribution of nuclear inhomogeneities.

[the dashed areas correspond to the experimental uncertainty as evaluated from the code of ref.7] 
The samples were placed in a $1.4 \mathrm{~T}$ magnetic field [3-5], in order to distinguish the nuclear SANS scattering (parallel to the magnetic field) from the magnetic scattering (both nuclear and magnetic scattering occur perpendicularly to the field). The neutron intensities scattered from the samples were recorded by a two-dimensional detector. The nuclear cross sections (parallel to the field) of irradiated and non-irradiated samples are reported in fig. 1a. The cross sections in a direction perpendicular to the magnetic field (nuclear + magnetic cross sections) are reported in figs. $1 \mathrm{~b}$. We considered the difference of SANS signal between irradiated and non-irradiated samples as mainly due to the microstructural inhomogeneities induced by the dual beam irradiation. This difference is reported for the nuclear case in fig.2a. Assuming a spherical shape of the inhomogeneities, their size distribution function $N(R)$ was then determined using the method described in ref. [7]: the results are reported in fig. $2 \mathrm{~b}$. Fig. $2 \mathrm{c}$ reports the corresponding volume distribution $N(R) \cdot V(R)$, being $V(R)=4 / 3 \pi R^{3}$.

The SANS curve corresponding to the size distribution of fig. $2 \mathrm{~b}$ are compared with the experimental points in fig. $2 a$.

Commenting the figure $2 \mathrm{~b}$, a remarkable population of inhomogeneities with radii $R>10 \mathrm{~nm}$ is present. The $N(R)$ function is quite high for smaller radii (1-5 $\mathrm{nm}$ approximatively) but in this region the associated error band is quite large: this range corresponds in fact to the highest Q's in fig.1, where the experimental error is larger. On the other side, since TEM observations on similarly irradiated MANET samples showed the presence of bubbles having average diameter of $\sim 5 \mathrm{~nm}$, further SANS and TEM measurements should be performed: SANS measurements extending to larger $Q$ values in order to more accurately characterize the smallest bubbles and TEM measurements aiming to detect whether larger bubbles are present.

\section{REFERENCES}

[1] R.L.Klueh, K.Ehrlich, F.Abe, J.Nucl.Mater. 191-194(1992),116

[2] D.Kaletta, J.Nucl.Mater. 131-134 (1985),878

[3] G.Albertini, F.Carsughi, R.Coppola, F.Rustichelli, W.A.H.M.Vlak, C.Van Dijk, J. Nucl. Mater. 179-181 (1991) 706.

[4] G.Albertini, F.Carsughi, R.Coppola, F.Rustichelli, D.Schwahn, G.Mercurio, Nucl. Instr. \& Meth. A321 (1992) 381.

[5] G.Albertini, F.Carsughi, R.Coppola, W.Kesternich, G.Mercurio, F.Rustichelli, D.Schwahn, H.Ullmaier, J. Nucl. Mat. 191-194 (1992) 1327.

[6] R.Lindau, A.Möslang, J. Nucl. Mat. 179-181 (1991) 753.

[7] M.Magnani, P.Puliti, M.Stefanon, Nucl. Instr. \& Meth. A271 (1988) 611. 